\title{
ФОРМИРОВАНИЕ ДИЗАЙН-МЫШЛЕНИЯ ОБУЧАЮЩИХСЯ В УСЛОВИЯХ ДОМА НАУЧНОЙ КОЛЛАБОРАЦИИ ИМ. К.А.ВАЛИЕВА: ИЗ ОПЫТА РАБОТЫ
}

\section{FORMATION OF DESIGN-THINKING OF STUDENTS IN THE CONDITIONS OF THE HOUSE OF SCIENTIFIC COLLABORATION THEM K. A. VALIEVA: EXPERIENCE}

\section{Latipova}

Summary: The relevance of the formation of design thinking of students is due to the need to use the principles and techniques of design in design and research and art and design activities, as well as to prepare the younger generation for the choice of the profession of the future, regardless of the field of activity. In this article, on the basis of fundamental research, the definitions of the term "design thinking" are revealed, its tools and processes, which made it possible to design the content and implement the scientific and educational project "School of Art Design" in the conditions of the "House of Scientific Collaboration named after Kamil Akhmetovich Valiev" based on Yelabuga Institute KFU.

Keywords: дизайн-мышление, обучающиеся, научно-образовательный проект «Школа Арт-дизайна», тематическое планирование, кейс, арт-объект.
Латипова Лилия Николаевна к.n.н., доцент, Елабужский институт (филиал) ФГАОУ ВО «Казанский (Приволжский) федеральный университет» latipova-liliya@mail.ru

Аннотация: Актуальность формирования дизайн-мышления обучающихся обусловлена необходимостью использования принципов и приемов дизайна в проектно-исследовательской и художественно-дизайнерской деятельности, а также подготовке подрастающего поколения к выбору профессии будущего вне зависимости от сферы деятельности. В данной статье на основе фундаментального исследования выявлены дефиниции термина «дизайнмышление» его инструменты и процессы, что позволили спроектировать содержательное наполнение и реализовать научно-образовательный проект «Школа Арт-дизайна» в условиях «Дом научной коллаборации имени Камиля Ахметовича Валиева» на базе Елабужского института ФГАОУ ВО КФУ.

Ключевые слова: дизайн-мышление, обучающиеся, научно-образовательный проект «Школа Арт-дизайна», тематическое планирование, кейс, артобъект. оздание отдельного структурного подразделения «Дом научной коллаборации имени Камиля Ахметовича Валиева» на базе Елабужского института ФГАОУ ВО КФУ, как структурного подразделения Казанского федерального университета, способствует достижению целей, показателей и результатов федерального проекта «Успех каждого ребенка» национального проекта «Образование», в том числе результата 1.9. федерального проекта «Созданы ключевые центры дополнительного образования детей, реализующие дополнительные общеобразовательные программы в организациях, осуществляющих образовательную деятельность по образовательным программам высшего образования, в том числе участвующим в создании научных и научно-образовательных центров мирового уровня или обеспечивающих деятельность центров компетенций Национальной технологической инициативы». Так случилось, что суть методологии дизайн-мышления, его основные принципы как нельзя лучше соответствуют ценностям нашего проекта в Доме научной коллаборации им К.А. Валиева, участниками которого являются обучающиеся общеобразовательных организаций и студенты СПО.
Будущее требует, чтобы в распоряжении ведущих специалистов и руководителей имелся набор разных инструментов дизайна и инструментов анализа, предназначенных для ведения отлаженного бизнеса в более стабильном мире. Как и любой процесс, дизайн-мышление практикуется на разных уровнях людьми с разными талантами и возможностями.

В Свободной энциклопедии термин «Дизайн-мышление» декларируют, как: «...методология решения инженерных, деловых и прочих задач, основывающаяся на творческом, а не аналитическом подходе» [1].

«Дизайн-мышление относится к когнитивному, стратегическому и практические процессы, с помощью которых разрабатываются концепции дизайна (предложения по продуктам, зданиям, машинам, коммуникациям и т. д.)» утверждает Star-wiki [2].

Интересное определение дает Мария Сташенко, основатель и партнер лаборатории Wonderfull, директор АНО «Центр дизайн-мышления»: «Дизайн-мышление это метод и подход к работе, когда на первое место в 
своей деятельности создатели ставят интересы и возможности человека, пользователя будущих продуктов или услуг. Для того, чтобы создавать действительно полезные решения, есть множество инструментов, которые помогают узнать опыт людей, обобщить его и сгенерировать новые идеи» [3].

«Дизайн-мышление (design thinking) - способ разработки продуктов и услуг в условиях неопределенности, основанный на дизайнерских подходах и эвристических приемах» такому определению придерживаются команда с КУ Сбербанка [4].

Мария Сташенко, как основатель лаборатории Wonderfull [5] утверждает: «...чтобы решить проблему, найти эффективное решение, нужно сначала провести исследование, точно определить проблему, затем конкретно сфокусироваться на «болевых точках», сгенерировать идеи, выбрать лучшее, создать прототип и протестировать его».

Жанна Лидтка и Тим Огилви в своей работе «Думай как дизайнер. Дизайн-мышление для менеджеров» выделили десять инструментов дизайн-мышления: Визуализация; Карта эмпатии; Анализ цепочки создания ценностей; Майнд-мэппинг (генерация идей); Брейншторминг (генерация новых возможностей и новых альтернативных бизнес-моделей); Разработка концепций; Тестирование гипотез; Горячее прототипирование; Кодизайн с пользователями; Тестовый запуск [7].

Мы солидарны с данными дефинициями термина «дизайн-мышление»: как видим - он интересует и затрагивает все сферы деятельности человека, в том числе и бизнес, как восприятие творческого процесса. Тем не менее, можно отметить, что сам процесс по дизайнмышлению обучающихся школьного возраста можно показать как некую логическую цепочку взаимосвязанных действий: кейс-задача - карта эмпатии - анализ - дизайн-проектирование - тест-гид - оценка - доработка* масштабирование. Каждый этап цикличен, свойственен проектной деятельности, позволяет разработчику, а в данном случае это наши обучающиеся школьного возраста полностью погружаются в опыт пользователя и даже заказчика.

Отличительной особенностью нашего Дома научной коллаборации и К.А. Валиева, является то, что он функционирует при Казанском федеральном университете, кадровый потенциал формируется из числа профессорско-преподавательского состава и магистров; образовательные программы дополненного образования обучающихся школьного возраста комплектуются с учетом базы и реализуемых профилей подготовки бакалавриата и магистратуры вуза. Так, в 2021 календарном году помимо образовательных программ нами были разработаны и реализованы образовательные тематические интенсивы для школьников в каникулярное время научно-технологические проект «Школа Новых Технологий», научно-образовательные проекты «Школа Арт-дизайна» и «Занимательная биология». Каждый из интенсивов уникален. Например, при реализации проекта «Школа Новых Технологий» были привлечены интеллектуальные партнеры РобоЛенд, г. Казань. Проект имел успех и был реализован в два уровня (весна и лето 2021 г). Большой популярностью пользовался и тематический проект по интересам «Школа Арт-дизайна». Все эти проекты объединяет инструмент - кейс и проектная деятельность. Разберем более детально один из проектов: «Школа Артдизайна».

Дополнительная общеобразовательная общеразвивающая программа «Школа Арт-дизайна» имеет художественную направленность.

Актуальность программы заключается в своевременном выявлении и развитии у обучающихся интеллектуальных и творческих способностей, интереса к художественно-исследовательской и дизайнерской деятельности; создания современных инновационных площадок для формирования дизайн-мышления. Дизайн на сегодняшний день является той отраслью, в которой вполне успешно можно реализовать задачи интеллектуального развития детей и молодежи и приобщения их к современным технологиям. Отличительные особенности программы и новизна заключается в использовании современных методик организации и проведения занятий в инновационной среде обучения в условиях Дома научной коллаборации им. К.А. Валиева.

Категория обучающихся (адресат программы) - программа ориентирована на школьников в возрасте 11-14 лет, желающих ознакомится с современными дизайнтехнологиями моделирования и конструирования творческого продукта. Обучающиеся должны иметь представление об основах работы в среде Windows.

Программа реализуется через проведение следующих видов учебных занятий и учебных работ: решение кейсов, практические занятия, интерактивные мастерские, мастер-классы, выполнение самостоятельной работы, презентация в формате постеров, творческий проект и прочие.

Цель программы - развитие художественных способностей обучающихся и формирование дизайн-мышления за счет традиционно-изобразительных, визуальных и цифро-графических решений с использованием кейстехнологий по дизайну. 
Основные разделы, формирующие дизайн-мышление научно-образовательного проекта «Школа Артдизайна» представлены в Таблице 1.

Например, Кейс 5. Handmade. Утюжки

Onисание проблемной ситуации: Как появляются новые предметы? Перед вами бытовой предмет - утюг. Попробуйте визуально показать его в прошлом...

\section{Из каких деталей он состоит?}

Определите его фукнционал. А теперь в современном мире и будущем...

\section{Как можно сделать его актуальным?}

Уровень кейса: данный кейс соответствует в пределе 3 и 4 уровня сложности, ориентированный на модификацию и получение дизайн-продукта в материале.

Место кейса в структуре образовательной программы: выполняется в разделе Design предметной среды и имиджа. Объем трудоемкости 6 часов.

\section{Цели: освоение навыков дизайн-проектирования.}

Минимально необходимый и формируемый уровень компетенций: дизайнерский скетчинг, креативность, творческий подход, чувство стиля и композиции, способность к макетированию и формообразованию, аккуратность и точность выполнения задач дизайн-проекта, навык презентации.

Предполагаемые образовательные результаты: данный кейс позволяет ввести обучающихся в основы проектно-исследовательской и художественно-дизайнерской деятельности, макетирование Арт-объекта «Утюжок», наделяя его определенными функциональными и эстетическими свойствами.

Прочедуры и формы выявления образовательного результата: презентация Арт-объектов Handmade «Утюжок». Тест-гид.
Подведение промежуточных итогов реализуется в рамках защиты результатов индивидуального выполнения Кейса 1, Кейса 2 , Кейса 3, Кейса 4 и Кейса 5.

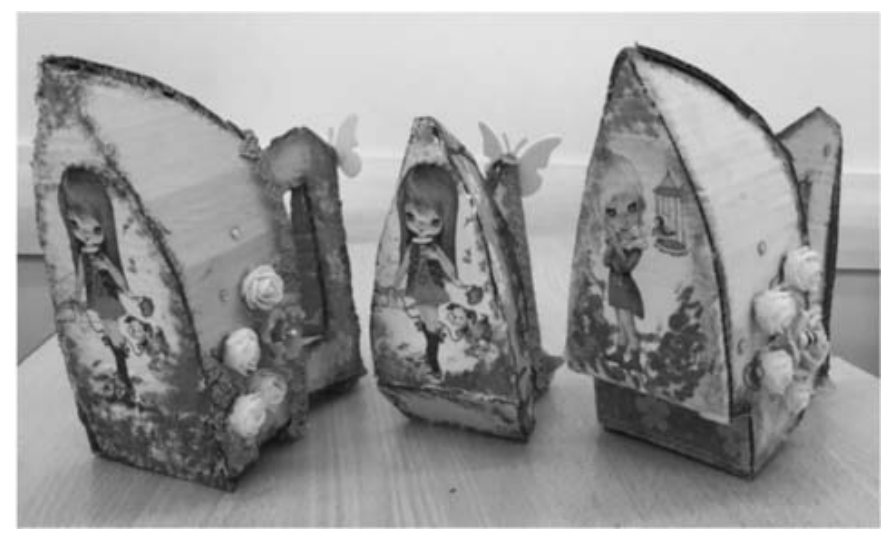

Рис. 1. Арт-объект «Утюжки» обучающихся 3 отряда, младшая группа

Например, аттестация раздела «Web design» проходит в виде презентации и результатов Тест-гида. Обучающиеся на протяжении 6 часов создавали сайты, наполняли и оформляли контент, по завершению которого делалась выгрузка. При этом каждый получил свою визитку-карту (Рис. 2).

Особенностью нашей проекта «Школа Арт-дизайна» является то, что он несет в себе еще и воспитательную функцию. В соответствии с режимом дня Школы Артдизайна наши обучающиеся пребывали в нем с 8.30 до 15.00 на протяжении 12 дней. Каждый день мы проводили в интенсивном погружении. Например, подготовили образовательно-развлекательный план, с учетом календарных мероприятий, так или иначе относящихся к дизайн-индустрии, творчеству и искусству и старались «переносить» их на занятия.

В проведении данных мероприятий Школы Артдизайна активно участвовали наши студенты-бакалавры Елабужского института (филиала) Казанского (Приволжского) федерального университета, обучающиеся по профилю 44.03.04 Профессионально обучение (по отраслям), профиль «Декоративно-прикладное искусство и дизайн». Наши обучающиеся были полностью погру-

Таблица 1.

Тематическое планирование научно-образовательного проекта «Школа Арт-дизайна»

\begin{tabular}{|l|l|l|}
\multicolumn{1}{|c|}{ Название раздела } & \multicolumn{1}{|c|}{ Кейсы, раскрывающие содержание темы } & Формы контроля (аттестации) \\
\hline Графический дизайн & Кейс 1 & Просмотр работ в графических редакторах по отрядам \\
\hline Фэшн дизайн. & Кейс 2 & Просмотр эскизов в технике Fаshion-скетчинг по отрядам \\
\hline Скетчинг & Кейс 3 & Просмотр эскизов в технике скетчинг по отрядам \\
\hline Web design & Кейс 4 & Презентация сайта по QR-кодам и медиа-презентаций по отрядам \\
\hline Design предметной среды и имиджа & Кейс5 & Презентация арт-объектов Наndmade по отрядам \\
\hline
\end{tabular}




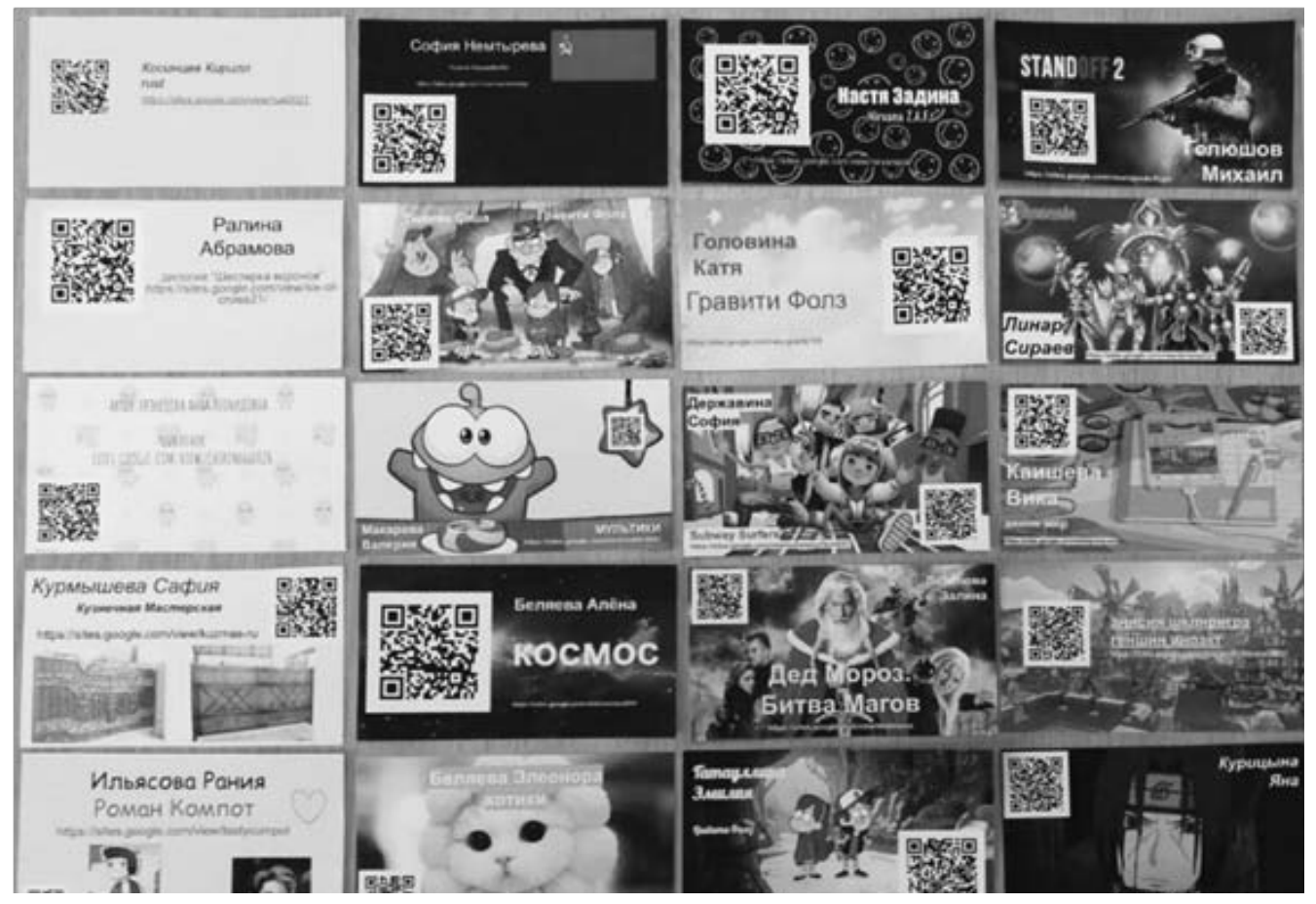

Рис. 2. Визитки-карты Кейса 4, раздела «Web design»

Таблица 2.

План мероприятий научно-образовательного проекта «Школа Арт-дизайна»

\begin{tabular}{|c|c|c|}
\hline Дата & Календарное событие & Мероприятие/занятия \\
\hline 05.07.2021 г & $\begin{array}{l}\text { День механического карандаша } \\
\text { Международный День трудоголиков (Workaholics Day) }\end{array}$ & $\begin{array}{l}\text { Коворкинг по станциям («Медуза», «Айсберг», «Болото» и др.) } \\
\text { /Скетчинг «Нагрудная медаль» }\end{array}$ \\
\hline 06.07.2021 г & День лета и поэзии (Эйно Лейно) & $\begin{array}{l}\text { Квест «Поэзия Лета» } \\
\text { /коллаж «Лето» (графические планшеты) }\end{array}$ \\
\hline 07.07.2021 г & День воинской славы России & $\begin{array}{l}\text { Историческая квест-игра «День воинской славы России» } \\
\text { / ЗD моделирование: статуэтка }\end{array}$ \\
\hline 08.07.2021 г & Всероссийский день семьи, любви и верности & $\begin{array}{l}\text { Квест-игра «Секреты семейного счастья: сундучок» } \\
\text { / Web design: оформление странички-рубрики сайта «Моя семья» }\end{array}$ \\
\hline 09.07.2021 г & $\begin{array}{l}\text { День сахарного печенья (Sugar Cookie Day) } \\
\text { День моды (Fashion Day). }\end{array}$ & $\begin{array}{l}\text { Квест «Печем печенье» } \\
\text { / Fashion-скетчинг «Мода: школа -2021» } \\
\text { Handmade: броши }\end{array}$ \\
\hline 10.07.2021 г & День котенка & $\begin{array}{l}\text { Квест «Три кота» } \\
\text { /Скетчинг «Котики» }\end{array}$ \\
\hline 11.07.2021 г & $\begin{array}{l}\text { Всемирный день шоколада (World Chocolate Day) } \\
\text { День художника по свету (День светооператора) } \\
\text { День российской почты }\end{array}$ & $\begin{array}{l}\text { Квест-игра «Страна Шоколандия» } \\
\text { /Скетчинг «Почтовая марка», } \\
\text { Fashion-скетчинг }\end{array}$ \\
\hline 12.07.2021 г & День фотографа & $\begin{array}{l}\text { Квест «Внимание! Фото» } \\
\text { / Графический дизайн: фоторедактор }\end{array}$ \\
\hline 13.07.2021 г & Международный день головоломки. & Квест «Мир головоломок» \\
\hline 14.07.2021 г & День хаоса и беспорядка (Pandemonium Day) & $\begin{array}{l}\text { Квест - стоковые фотографии «Хаос и беспорядок» } \\
\text { / Web design Коллаж «Хаус» }\end{array}$ \\
\hline 15.07.2021 г & $\begin{array}{l}\text { Всемирный день навыков молодежи (World Youth Skills Day) } \\
\text { День рисования углем }\end{array}$ & $\begin{array}{l}\text { Workshop: от художника до дизайнера (мастеская) } \\
\text { /Fashion-скетчинг: техника уголя }\end{array}$ \\
\hline 16.07.2021 г & День рисования мелом на асфальте & $\begin{array}{l}\text { Квест-игра «Игра.Мел.Асфальт» } \\
\text { /Скетчинг на асфальте «Визитка: Здесь были МЫ»! }\end{array}$ \\
\hline
\end{tabular}


жены в среду дизайна и искусства. Деление на отряды (группа по 10-12 человек) осуществлялось по уровню развития: определяли входным тест-скетчингом. По завершению первого интенсива, каждый обучающихся получил свое портфолио.

Реализация научно-образовательного проекта «Шко- ла Арт-дизайна» осуществлялась на базе Дома научной коллаборации имени Камиля Ахметовича Валиева при Елабужском институте Казанского (Приволжского) федерального университета в рамках федерального проекта «Успех каждого ребенка» национального проекта «Образование». Благодарим всех за поддержку!

\section{ЛИТЕРАТУРА}

1. Википедия [Сайт]. - URL: https://ru.wikipedia.org/wiki/\%D0\%94\%D0\%B8\%D0\%B7\%D0\%B0\%D0\%B9\%D0\%BD-\%D0\%BC\%D1\%8B\%D1\%88\%D0\%BB\%D0\%B 5\%D0\%BD\%D0\%B8\%D0\%B5 (дата обращения: 19.07.2021).

2. Сайт star-wiki.ru [Сайт]. - URL: https://star-wiki.ru/wiki/Design_thinking (дата обращения: 19.07.2021).

3. Дизайн-мышление: истории из практики - URL: https://drive.google.com/file/d/1LLNiEE03upxDJ1eCiR_91PolYvjzP0vl/view (дата 0бращения: 23.07.2021).

4. Потребности и прототипы: как использовать дизайн-мышление в обучении?// EduTech - № 2 (14) - 2018. - URL: https://sberuniversity.ru/upload/ iblock/530/14_EduTech_demo.pdf (дата обращения: 25.07.2021).

5. Дизайн в цифровой среде - URL: https://tilda.education/courses/web-design/designthinking/\# (дата обращения: 25.07.2020).

6. Стрельникова В.Э. Дизайн-мышление как современный метод проектирования - URL: https://obe.ru/journal/vypusk-2019-g-4-16-dekabr/strelnikova-v-edizajn-myshlenie-kak-sovremennyj-metod-proektirovaniya/ (дата обращения: 23.07.2020).

7. Дизайн и бизнес: как создавать инновации, объединяя противоположности? - URL: https://www.marketing.spb.ru/lib-mm/tactics/Design_Thinking.htm (дата обращения: 22.07.2020).

(c) Латипова Лилия Николаевна (latipova-liliya@mail.ru).

Журнал «Современная наука: актуальные проблемы теории и практики»

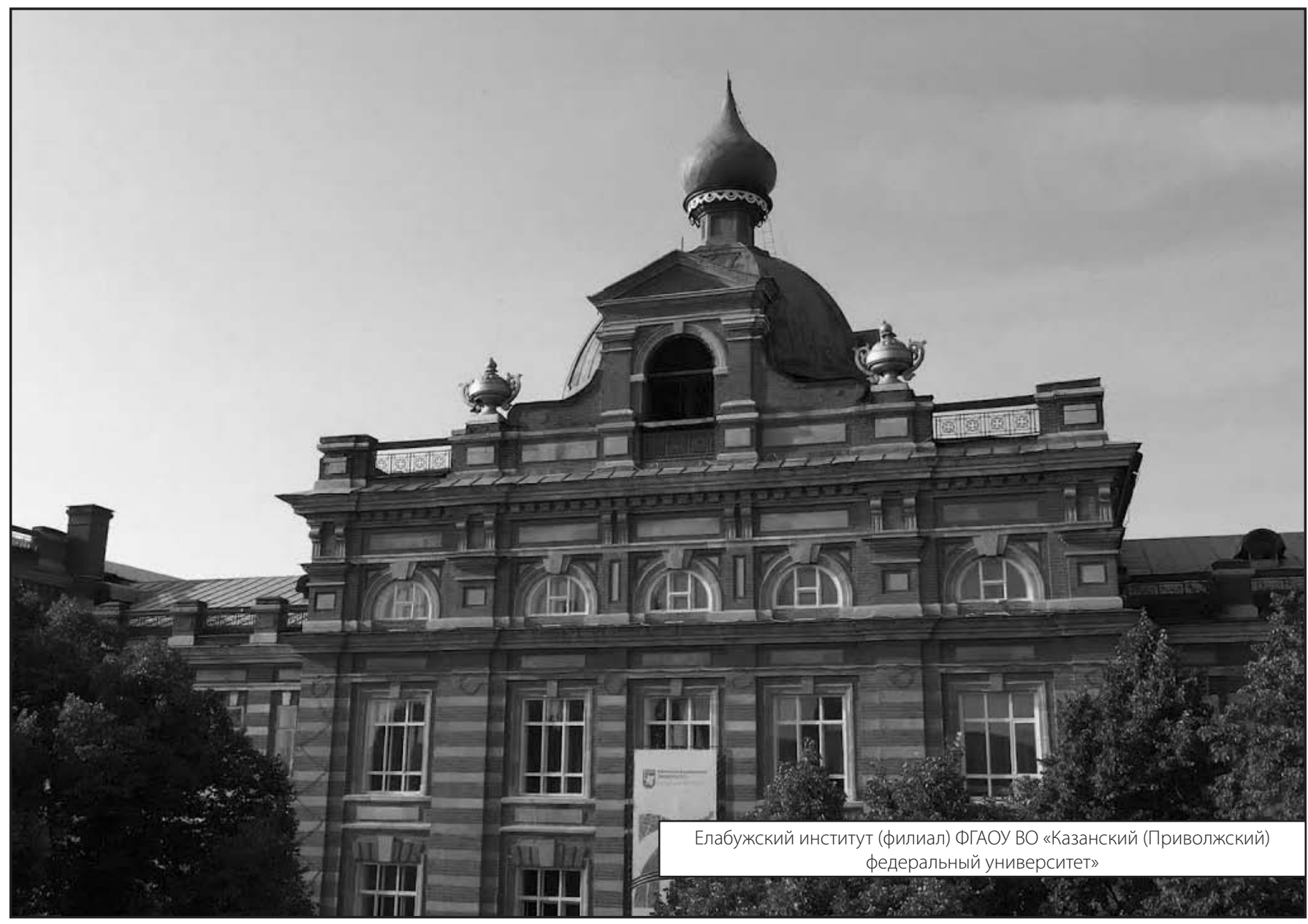

